1. MBBS, FCPS (Psychiatry) Assistant Professor

Department of Psychiatry \&

Behavioral Sciences

Services Institute of Medical

Sciences/Services Hospital Lahore.

2. MBBS

Medical Officer

Primary and Secondary Healthcare Department, Punjab

3. MBBS

Medical Officer

Women Medical Officer Basic Health

Unit Ramdial District Jehlum

Primary and Secondary Healthcare

Department, Punjab.

4. MBBS, FCPS (Psychiatry)

Associate Professor of Psychiatry \&

Behavioral Sciences.

M. Islam Medical and Dental

College, Gujranwala.

5. MBBS, FCPS (Psychiatry)

Senior Registrar

Department of Psychiatry \&

Behavioral Sciences.

Services Institute of Medical

Sciences/Services Hospital Lahore.

6. MBBS

Resident/PG Trainee Psychiatry \&

Behavioral Sciences.

Services Institute of Medical

Sciences/Services Hospital Lahore.

Correspondence Address:

Dr. Nauman Mazhar

Psychiatry \& Behavioral Sciences

Services Institute of Medical Sciences/

Services Hospital, Lahore.

nauman.mazhar@gmail.com

Article received on:

20/01/2020

Accepted for publication:

20/03/2020

\section{A STUDY OF COMPONENTS OF BEHAVIORAL ADDICTION TO SOCIAL MEDIA USE IN CURRENT GENERATION OF PAKISTANI YOUTH.}

\author{
Nauman Mazhar', Touseef Bilal Khan², Khansa Zafar ${ }^{3}$, Shahid Hameed Warris ${ }^{4}$, Sadia Nikhet ${ }^{5}$, \\ Amina Tahir ${ }^{6}$
}

ABSTRACT... Information Technology has brought significant changes to the human social interaction \& behaviors. Behavioral addiction to social media use is a rather novel concept in psychiatric "classification of diseases". Some foreign studies have reported it to be as high as $29.5 \% .^{7,8}$ There is need to study this relatively neglected area specially among our youth. This will help provide reliable data to understand the magnitude of current problem. Objectives: To study the Components of Behavioral addiction to Social Media use: Conflict, Mood Modification, Relapse, Salience, Tolerance and Withdrawal, among the youth in Pakistan. Study Design: Cross-sectional study. Setting: Department of Psychiatry Services Institute and Medical Sciences, Lahore. Period: March 2019 to May 2019. Material \& Methods: Among University students was conducted Purposive sampling technique was employed. Questionnaire forms were given to students of a University. Each questionnaire had 12 questions. There were specific questions for each component of addiction: Conflict, Mood Modification, Relapse, Salience, Tolerance and Withdrawal. Each respondent's bio-data, preferred social networking medium and frequency of social media use were recorded. They were also asked about their perception about excessive social media use. The responses were based on Likert scale. The respondents were asked to give the single best response to each question. A total of 210 responses were obtained. They were assessed using the software, IBM SPSS version 25. Results: The sample population reported positive for all the components of addiction tested. The majority (greater than $50 \%$ ) of responses for each component were in "Always" to "Sometimes" range of Likert scale. Conclusion: The current generation of Pakistani youth might be suffering from Behavioral Addiction to Social Media use.

Key words: $\quad$ Behavioural Addiction, Internet, Social Media, Youth.

Article Citation: Mazhar N, Khan TB, Zafar K, Warris SH, Nikhet S, Tahir A. "A study of components of behavioral addiction to social media use in current generation of Pakistani youth." Professional Med J 2020; 27(8):1680-1685. DOI: 10.29309/TPMJ/2020.27.08.4494

\section{INTRODUCTION}

The Age of Information Technology has brought significant changes to the human social interaction. Means of communication have evolved. Social media and online social interactions have become key tools for sharing experiences ${ }^{1}$, communicating with peers ${ }^{2}$ and transferring knowledge. ${ }^{3}$ The possibilities arising from these trends are endless, as are some of the problems.

The issues of cyber-bullying and harassment ${ }^{4}$, unintentional and uninvited exposure to sexual content $^{5}$, and psychological consequences of dependence on these media are just some of the challenges. ${ }^{6}$ Our fascination with social media and the ease of access to it has led to our dependence on it. Behavioral addiction to social media use is a rather novel concept.

Studies in Singapore and India have found $29.5 \%$ and $26 \%$ of sample population showing addiction to social media use..$^{7,8}$ Alarmingly, in both studies, more than a quarter of the population was found addicted to social media, indicating that a significant portion of general population may be suffering from this disorder.

Individuals afflicted by this behavioral problem have demonstrated several familial, academic 
and occupational problems. ${ }^{6}$ Extra 'Screen-time' causes sleep deprivation and sedentary habits. This may result in obesity and consequently, a higher risk of ailments associated with obesity: Hypertension, diabetes and coronary artery disease. ${ }^{9}$ Occupational efficacy deteriorates and work output decreases. ${ }^{10}$ In students, concentration in class is decreased and academic performance is adversely affected. ${ }^{11}$ Families suffer when one spouse fails to do their part in the home, with the other spouse bearing the extra burden. This leads to breakdown in relationships. ${ }^{12}$

Individuals with Behavioral addiction to social media use are more likely to display other psychological disorders as well. Attention Deficit Hyperactivity Disorder (ADHD), Obsessive Compulsive Disorder (OCD), anxiety, mania, narcissism, low self-esteem and depression ${ }^{13,7,14}$ have all been positively correlated with this addiction. Incidence of Substance Abuse Disorders, such as binge drinking ${ }^{15}$, has also been higher in such individuals. This should be of particular concern to psychologists, physicians and healthcare authorities.

The current generation of Pakistani youth has grown up experiencing the internet and social networking. It forms an integral part of their life. Studies in Pakistan have found internet addiction to be present in as much as $46 \%{ }^{11}$ and $26.8 \%$ of sample population. ${ }^{16}$ These astronomical figures imply a social and healthcare challenge of great magnitude.

Behavioral addictions have been described in DSM $\mathrm{V}$ and ICD XI as having several components..$^{19,20}$ These components have also been used extensively to study other behavioral addictions, such as mobile phone addiction ${ }^{21}$, Gambling addiction and online gaming addiction. ${ }^{19,20}$ Social media addiction has also been studied within the framework of these components. ${ }^{22,23,24,25}$ For the purpose of this research, we have calculated the incidence of six components of addiction in the youth of Pakistan: Conflict, Mood Modification, Relapse, Salience, Tolerance and Withdrawal.
Treatment interventions by psychiatrists and psychologists should be aimed at addressing the individual components of addiction. ${ }^{17}$ For this reason, knowing the incidence of each component of addiction is important.

\section{MATERIAL AND METHODS}

A cross-sectional study among university students of Pakistan was conducted. The duration was from March 2019 to May 2019. Purposive sampling technique was employed. Questionnaire forms were given to students. Each questionnaire had 12 questions. There were specific questions for each component of addiction: Conflict, Mood Modification, Relapse, Salience, Tolerance and Withdrawal. Each respondent's bio-data, preferred social networking medium and frequency of social media use were recorded. They were also asked about their perception about excessive social media use.

The responses were based on Likert scale. The respondents were asked to give the single best response to each question. A total of 210 responses were obtained. They were assessed using the software, IBM SPSS version 25.

\section{RESULTS}

A total of 210 complete forms were received. $98(46.7 \%)$ of the respondents were males and $112(53.3 \%)$ were females. Age vise distribution was: $1.4 \%$ below age of sixteen, $97.6 \%$ between sixteen and thirty years, and only $1 \%$ of sample population aged thirty-one and above. Therefore, the target age of 16-30 years was achieved in $97.6 \%$ of sample population.

Facebook remained the most popular medium, with $66.2 \%$ of sample population preferring it over other social media.

In terms of daily usage, $29 \%$ of respondents stated that they used social media more than 120 minutes daily, $21 \%$ between $31-60$ minutes, $19 \%$ between $61-90$ minutes, $15.7 \%$ used below 30 minutes, and $15.2 \%$ between $91-120$ minutes. Therefore, the majority used social media more than 2 hours daily. 
In response to the statement, "I feel that I am addicted to social media use:" $33.8 \%$ agreed, $32.4 \%$ remained neutral while $15.7 \%$ of respondents strongly agreed. This indicates that the population infers that social media usage is adversely affecting their lives.

Questions exploring the six components of behavioral addiction were individually assessed. The results are as follows:

\section{CONFLICT}

\section{Intra-psychic}

In response to the statement, "I feel that my work output decreases because of social media use", $31.9 \%$ said sometimes, while $27.6 \%$ responded with often and $14.8 \%$ with very often. This supports the presence of intra-psychic conflict in the population.

\section{Inter-personal}

Moreover, the response to "People around me remark on my social media usage" $23.8 \%$ stated sometimes, $22.4 \%$ said often and $17.1 \%$ said very often, displaying inter-personal conflict as well.

\section{Mood Modification}

In response to the statement, "I feel my mood improve when using Social Media. I feel happier, more content and freer from worries"; $30.3 \%$ said Sometimes, followed by $19 \%$ with Often, and $16.2 \%$ with Never.

\begin{tabular}{|c|c|c|c|c|c|}
\hline \multicolumn{2}{|c|}{ Age of Sample Population } & \multicolumn{2}{|c|}{ Preferred Social Medium } & \multicolumn{2}{|c|}{ Time Spent in Minutes Daily } \\
\hline $17-21$ & $51.0 \%$ & Other & $33.8 \%$ & $30-60$ & $21.0 \%$ \\
\hline $26-30$ & $5.2 \%$ & & & $90-120$ & $15.2 \%$ \\
\hline Over 30 & $1.0 \%$ & & & More than 120 & $29.0 \%$ \\
\hline
\end{tabular}

\begin{tabular}{|c|c|}
\hline \multicolumn{2}{|c|}{ Self-Perception about social media addiction } \\
\hline Strongly agree & $15.7 \%$ \\
\hline Agree & $33.8 \%$ \\
\hline Neutral & $32.4 \%$ \\
\hline Disagree & $14.8 \%$ \\
\hline Strongly Disagree & $3.3 \%$ \\
\hline
\end{tabular}

In response to the statement, "I try to decrease the amount of time I spend using social media sites and fail" $28.6 \%$ stated sometimes, $26.7 \%$ said often, followed by $19 \%$ who said rarely. With the majority of responders in positive response category, withdrawal is exhibited by the population as well.

\section{Salience}

In response to the statement, "I check my social media sites before something else that I need to do", majority of the population said often (33.8\%), followed by sometimes $(31.9 \%)$, followed by very often (19\%). This supports the presence of salience in the sample population.

\section{Tolerance}

In response to the statement, "I spend more time than intended on Social Media", 33\% said often, $26.7 \%$ said sometimes, and $22.4 \%$ said very often. This supports the presence of tolerance in the population.

\section{Withdrawal}

In response to the statement, "I feel upset, angry, bored, outcast, disconnected from the world when I cannot access social media sites" an equal percentage $(22.9 \%)$ of sample population responded with often and sometimes, followed by $19 \%$ who said rarely. Thus, the majority of the population exhibited withdrawal as well. 


\begin{tabular}{|l|c|c|c|c|c|c|}
\hline & Very Often & Often & Sometimes & Rarely & Very Rarely & Never \\
\hline Conflict (Intra-Psychic) & $14.8 \%$ & $27.6 \%$ & $32.4 \%$ & $12.9 \%$ & $5.2 \%$ & $7.1 \%$ \\
\hline Conflict (Inter-Personal) & $17.1 \%$ & $22.4 \%$ & $23.8 \%$ & $16.7 \%$ & $10 \%$ & $10 \%$ \\
\hline Mood Modification & $8.4 \%$ & $19 \%$ & $30.3 \%$ & $12.7 \%$ & $13.4 \%$ & $16.2 \%$ \\
\hline Relapse & $8.1 \%$ & $26.7 \%$ & $28.6 \%$ & $19 \%$ & $9.5 \%$ & $8.1 \%$ \\
\hline Salience & $19 \%$ & $33.8 \%$ & $31.9 \%$ & $10 \%$ & $1.9 \%$ & $3.3 \%$ \\
\hline Tolerance & $22.4 \%$ & $31 \%$ & $26.7 \%$ & $12.9 \%$ & $3.8 \%$ & $3.3 \%$ \\
\hline Withdrawal & $14.3 \%$ & $22.9 \%$ & $22.9 \%$ & $16.2 \%$ & $9 \%$ & $14.8 \%$ \\
\hline & Table-III. Frequencies of responses for each category in percentage &
\end{tabular}

\section{DISCUSSION}

In our study, the results show that $29.5 \%$ of population use social media more than 2 hours daily. This significant amount of time spent on social media is a problem in itself. It has been linked with increased anxiety, and incidence of anxiety disorder. ${ }^{18}$ Decreasing the frequency of use of social media may be beneficial in all such individuals. ${ }^{17}$

Almost half $(49.5 \%)$ of the sample population is aware of its overuse of social media and believes it is 'addicted' to it. This result is consistent with studies done by Catherine So-kumTanget al and Shettar, M. in Singapore and India. ${ }^{7,8}$ These results are also similar to incidence of internet addiction in Pakistani populations. ${ }^{11,16}$ It implies that the society as a whole recognizes that social media overuse is a problem which afflicts it.

The sample population has shown high incidence of all six components of addiction tested. More than half of the responses for each category were in Always to Sometimes range of the scale. This is of particular importance because treatment strategies must be developed to target the individual components of this addiction. ${ }^{17}$

Salience was the component in highest frequency, with $84.7 \%$ of sample population showing it. This indicates that the population finds itself preoccupied with Social Media use. It hampers their other activities of daily life. ${ }^{6}$

This was followed by Tolerance at $80.1 \%$. The sample population feels the urge to increase the amount of time spent online.74.8\% of sample population reported intra-psychic Conflict. Self- perception about the negative consequences of excess time spent online is relatable to this component. Inter-personal Conflict was also positive (63.3\%). With Social media use occupying a significant amount of time of one's routine, the people around him are affected. Family relations may become strained. ${ }^{10,11}$ This may lead to reactionary conflicts.

Withdrawal was reported by $60.1 \%$ of sample population. It indicates that discontinuing use of social media evokes negative emotions within the individuals. Ba'nyai et al found this component to be have the highest incidence in their study. ${ }^{22}$

Mood Modification showed the lowest incidence rates at $57.7 \%$. It is subjective and subject to personal bias. However, overuse of social media has been documented to cause adverse emotional reactions such, as depression and anxiety. ${ }^{17,18}$

This study had certain limitations. Cross-sectional model was employed. Therefore, the causality could not be established. Purposive Sampling technique was employed. It has a high probability of sampling bias. This sampling technique is considered to be a poor representative of entire population.

Future research may be done by applying longitudinal study models, identifying other factors associated with this disorder. Causality may be established. Treatment or intervention modalities should also be researched.

Similar studies may be done by Simple Random sampling as a better representative of Pakistani 
populations. Stratified sampling technique for particular groups, such as students or healthcare professionals, may also be employed.

\section{CONCLUSION}

The sample population has reported positive for the six components of addiction tested. Moreover, the population is aware of its overuse of social media platforms being a problem.

\section{Acknowledgement}

We express our gratitude to the research participants and volunteers in the study.

Copyright@ 20 Mar, 2020.

\section{REFERENCES}

1. Karapanos E, Teixeira P, Gouveia R. Need fulfillment and experiences on social media: A case on Facebook and WhatsApp. Computers in Human Behavior. 2016 Feb 1; 55:888-97.

2. Bayer JB, Ellison NB, Schoenebeck SY, Falk EB. Sharing the small moments: ephemeral social interaction on Snapchat. Information, Communication \& Society. 2016 Jul 2; 19(7):956-77.

3. Arnaboldi V, Conti M, Passarella A, Dunbar RI. Online social networks and information diffusion: The role of ego networks. Online Social Networks and Media. 2017 Jun $1 ; 1: 44-55$.

4. Chen L, Ho SS, Lwin MO. A meta-analysis of factors predicting cyberbullying perpetration and victimization: From the social cognitive and media effects approach. New Media \& Society. 2017 Aug; 19(8):1194-213.

5. Lewis L, Somers JM, Guy R, Watchirs-Smith L, Skinner SR. 'I see it everywhere': young Australians unintended exposure to sexual content online. Sexual health. 2018 Jul; 15(4):335-41.

6. Siddiqui $S$, Singh T. Social media its impact with positive and negative aspects. International Journal of Computer Applications Technology and Research. 2016; 5(2):71-5.

7. Tang CS, Koh YY. Online social networking addiction among college students in Singapore: Comorbidity with behavioral addiction and affective disorder. Asian journal of psychiatry. 2017 Feb 1; 25:175-8.
8. Shettar M, Karkal R, Kakunje A, Mendonsa RD, Chandran VM. Facebook addiction and loneliness in the postgraduate students of a university in southern India. International Journal of Social Psychiatry. 2017 Jun; 63(4):325-9.

9. Tsitsika AK, Andrie EK, Psaltopoulou T, Tzavara CK, Sergentanis TN, Ntanasis-Stathopoulos I, Bacopoulou F, Richardson C, Chrousos GP, Tsolia M. Association between problematic internet use, sociodemographic variables and obesity among European adolescents. The European Journal of Public Health. 2016 Apr 25; 26(4):617-22.

10. Zivnuska S, Carlson JR, Carlson DS, Harris RB, Harris KJ. Social media addiction and social media reactions: The implications for job performance. The Journal of social psychology. 2019 Mar 1:1-5.

11. Khan MA, Alvi AA, Shabbir F, Rajput TA. Effect of internet addiction on academic performance of medical students. Journal of Islamic International Medical College. 2016; 11(2):48-51.

12. Ali A, Lodhi RN. How Facebook addiction affects the personal life of addict students and their family: A case study of Pakistan. Paradigms. 2017; 11(2):184-9.

13. Andreassen CS, Billieux J, Griffiths MD, Kuss DJ, Demetrovics Z, Mazzoni E, Pallesen S. The relationship between addictive use of social media and video games and symptoms of psychiatric disorders: A large-scale cross-sectional study. Psychology of Addictive Behaviors. 2016 Mar; 30(2):252.

14. Malik S, Khan M. Impact of facebook addiction on narcissistic behavior and self-esteem among students. J Pak Med Assoc. 2015 Mar 1; 65(3):260-3.

15. Spilkova J, Chomynova P, Csemy L. Predictors of excessive use of social media and excessive online gaming in Czech teenagers. Journal of behavioral addictions. 2017 Oct 17; 6(4):611-9.

16. Khan KW, Ramzan M, Imran SS. How lonely are the Internet Users?. Rawal Medical Journal. 2016; 41(4):480-2.

17. Shensa A, Escobar-Viera CG, Sidani JE, Bowman ND, Marshal MP, Primack BA. Problematic social media use and depressive symptoms among US young adults: A nationally-representative study. Social Science \& Medicine. 2017 Jun 1; 182:150-7.

18. Vannucci A, Flannery KM, Ohannessian CM. Social media use and anxiety in emerging adults. Journal of affective disorders. 2017 Jan 1; 207:163-6. 
19. Cooper R. Diagnosing the diagnostic and statistical manual of mental disorders. Routledge; 2018 May 8.

20. Tanno LK, Chalmers $R$, Bierrenbach AL, Simons FE, Martin B, Molinari N, Annesi-Maesano I, Worm M, Cardona V, Papadopoulos NG, Sanchez-Borges $M$. Changing the history of anaphylaxis mortality statistics through the World Health Organization's International Classification of Diseases-11. Journal of Allergy and Clinical Immunology. 2019 Sep $1 ; 144(3): 627-33$.

21. Fidan H. Development and validation of the mobile addiction scale: the components model approach. Addicta: The Turkish Journal on Addictions. 2016 Jan 1; $3(3): 452-69$.

22. Bányai F, Zsila Á, Király O, Maraz A, Elekes Z, Griffiths MD, Andreassen CS, Demetrovics Z. Problematic social media use: Results from a large-scale nationally representative adolescent sample. PLoS One. 2017 Jan 9; 12(1):e0169839.
23. Hasan T, Yasir H. „Am IA Facebook Addict?” An Investigation of Facebook Addiction Using Personality Traits through SEM. Journal of Organisational Studies and Innovation. 2016 Dec 1; 3(4):15-30.

24. Baskaran S, Howe NC, Mahadi N, Ayob SA. Youth and social media comportment: A conceptual perspective. International Journal of Academic Research in Business and Social Sciences. 2017; 7(11):1260-77.

25. van den Eijnden RJ, Lemmens JS, Valkenburg PM. The social media disorder scale. Computers in Human Behavior. 2016 Aug 1; 61:478-87.

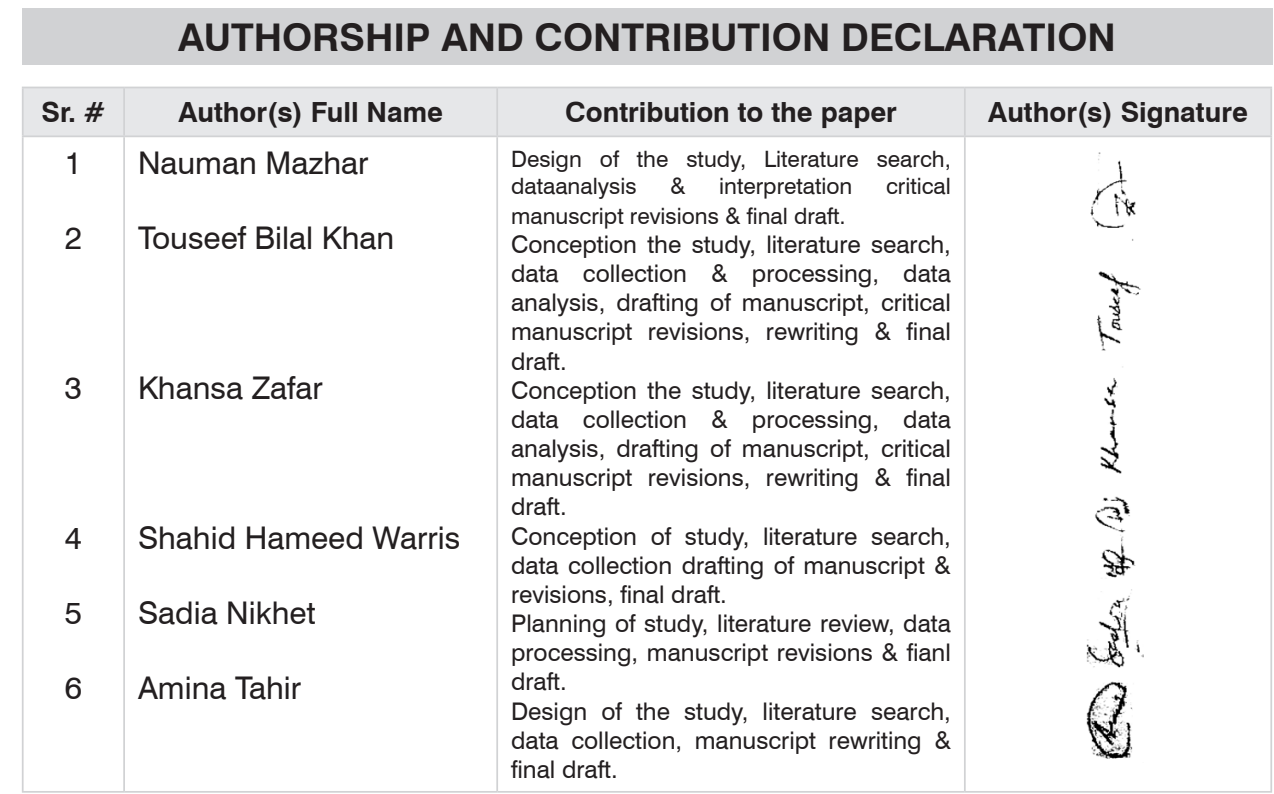

